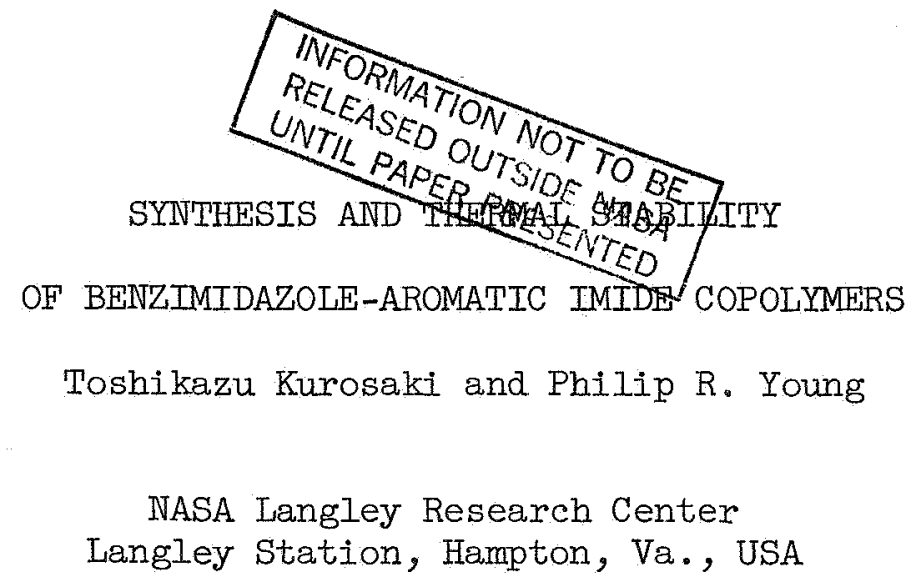

Presented at the IUPAC International Symposium on Macromolecular Chemistry

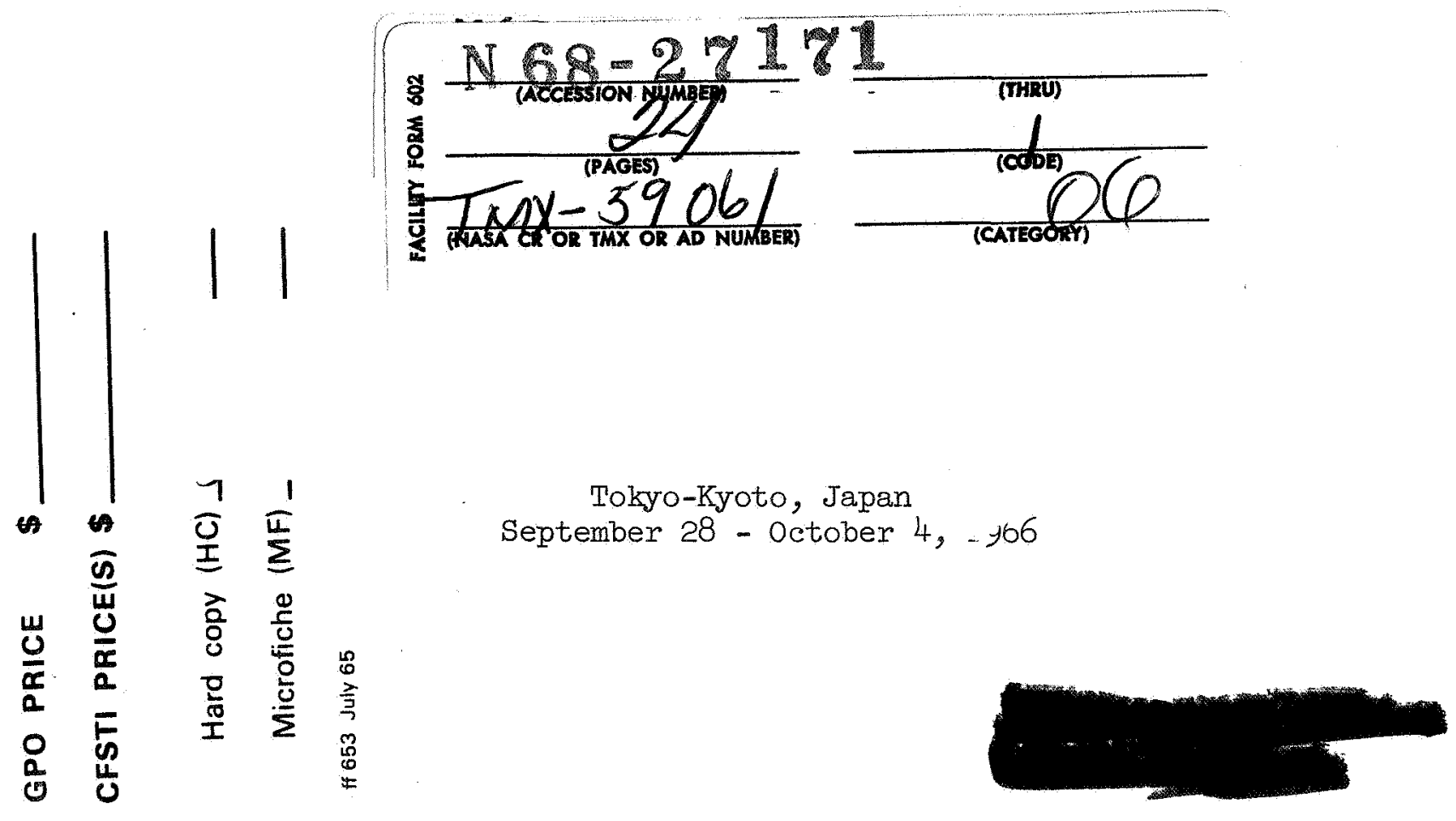




\section{Synthesis and Thermal Stability \\ of Benzimidazole-Aromatic Imide Copolymers}

Toshikazu Kurosaki* and Philip R. Young

National Aeronautics and Space Administration, Langley Research Center, Spacecraft Matexials Section, Hampton, Virginia

\section{Introduction}

Polybenzimidazoles $(1-3)$ and aromatic polyimides $(4-7)$ are well known for their high thermal stability. Recently Iwakura $(8)$ et al. tried to prepare thermally stable benzimidazolemamide copolymers from $2,2^{\prime}$-amino-pheny $1-5,5^{\prime}-$ dibenzimidazole and dicarboxylic acid dichlorides. The approach in this laboratory was to synthesize benzimidazolemaromatic imide copolymers from diaminophenylbenzimidazoles and aromatic dianhydrides. This approach established that by choosing appropriate polymerization methods and curing processes, polymer films of high strength and excellent thermal stability were obtained. Recently Preston and $B$ lack $(9)$ independently reported the results of their preparation of a series of copolymers, including one containing aromatic imide linkages contributed by one of the constituents.

This paper deals with the synthesis of various types of benzimidazolearomatic imide copolymers, and the measurement of their mechanical and thermal properties.

\section{Results and Discussion}

The following discussion is related to the synthesis and evaluation of four types of diaminophenylbenzimidazoles as diamine monomers. Each of the four diamines results from the reaction of either para- or metamaminobenzoic acid with an aromatic tetramine, such as $1,2,4,5$-tetraaminobenzene (TAB) or $3,3^{\prime}$-diaminobenzidine $(D A B):$<smiles>Nc1ccc(-c2nc3cc(N)ccc3[nH]2)cc1</smiles>

$2,2^{\prime}=$ di-p-aminopheny $1-5,5^{\prime}-$ dibenzimidazole $(D A B-p-A B)$

"NAS-MRC Resident Research Associate on leave of absence from the Tokyo Institute of Technology. 
${ }^{\mathrm{N}}$

2,2'-di-m-aminopheny $1-5,5^{\prime}$-dibenzimidazole $(D A B-m-A B)$<smiles>Nc1ccc(C2=Nc3cc4[nH]c3=CC(=NC=4c3ccc(N)cc3)N2)cc1</smiles>

$2,2^{\prime}-\mathrm{di}-\mathrm{p}-\mathrm{aminopheny} \mathrm{l}-2,6-i m i d a z o b e n z i m i d a z o l e(T A B-p-A B)$<smiles>Nc1cccc(-c2nc3cc4c(cc3[nH]2)NC(c2cccc(N)c2)N4)c1</smiles>

$2,2^{\prime}$-di-m-aminophenyl-2,6-imidazobenzimidazole (TAB-m-AB)

These four diamines were then reacted with either of the two dianhydrides:<smiles>O=c1oc(=O)c2cc3c(=O)oc(=O)c3cc12</smiles>

Pyromellitic dianhydride (PMDA), and<smiles>O=C(c1ccc2c(c1)C(=O)OC2=O)c1ccc2c(c1)C(=O)OC2=O</smiles>

$3,3^{\prime} 4,4^{\prime}$-benzophenone tetracarboxylic dianhydride (BPDA)

As a result of these reactions, eight types of polymers were synthesized from which films were prepared. The general reaction route is illustrated below by the combination of $D A B-p-A B$ and $P M D A$ in a typical polyimide synthesis.<smiles>[H][Y]1nc(-c2ccc(N)cc2)nc2ccccc12</smiles>

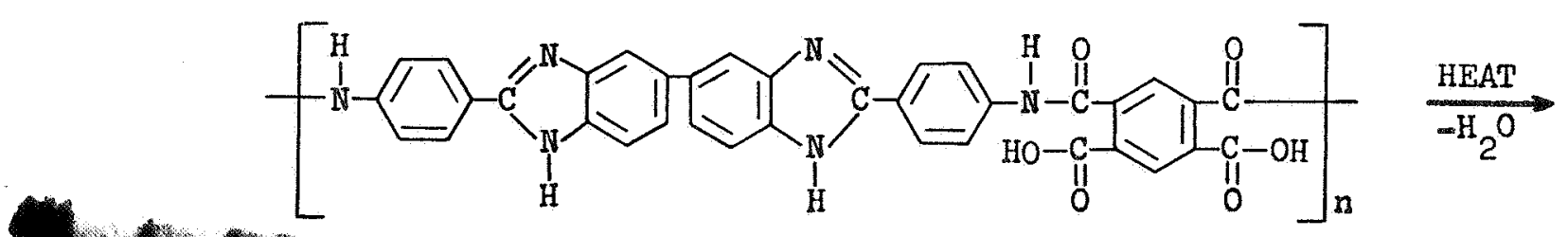


$\rightarrow+2$

The above mechanism was substantiated through the use of model compounds.

\section{Monomers}

The four monomers were prepared by Iwakura's method( 8$)$ of heating the appropriate aminobenzoic acids and tetraamines in polyphosphoric acid at $150^{\circ}-170^{\circ} \mathrm{C}$ for ten hours. All of the monomers prepared in this menner were highly complexed $(8)$ with solvent and dxying was accomplished only after heating at $280^{\circ}-300^{\circ} \mathrm{C}$. Although the specific nature of the complex could not be confirmed from the infrared spectra of the undried and dried products (Figs. 1 and 2), it was assumed that complexing had occurred with alcohol and/or water, as indicated by the virtual disappearance of the $-\mathrm{OH}$ absorption peak in the $3400 \mathrm{~cm}^{-1}$ region on drying.
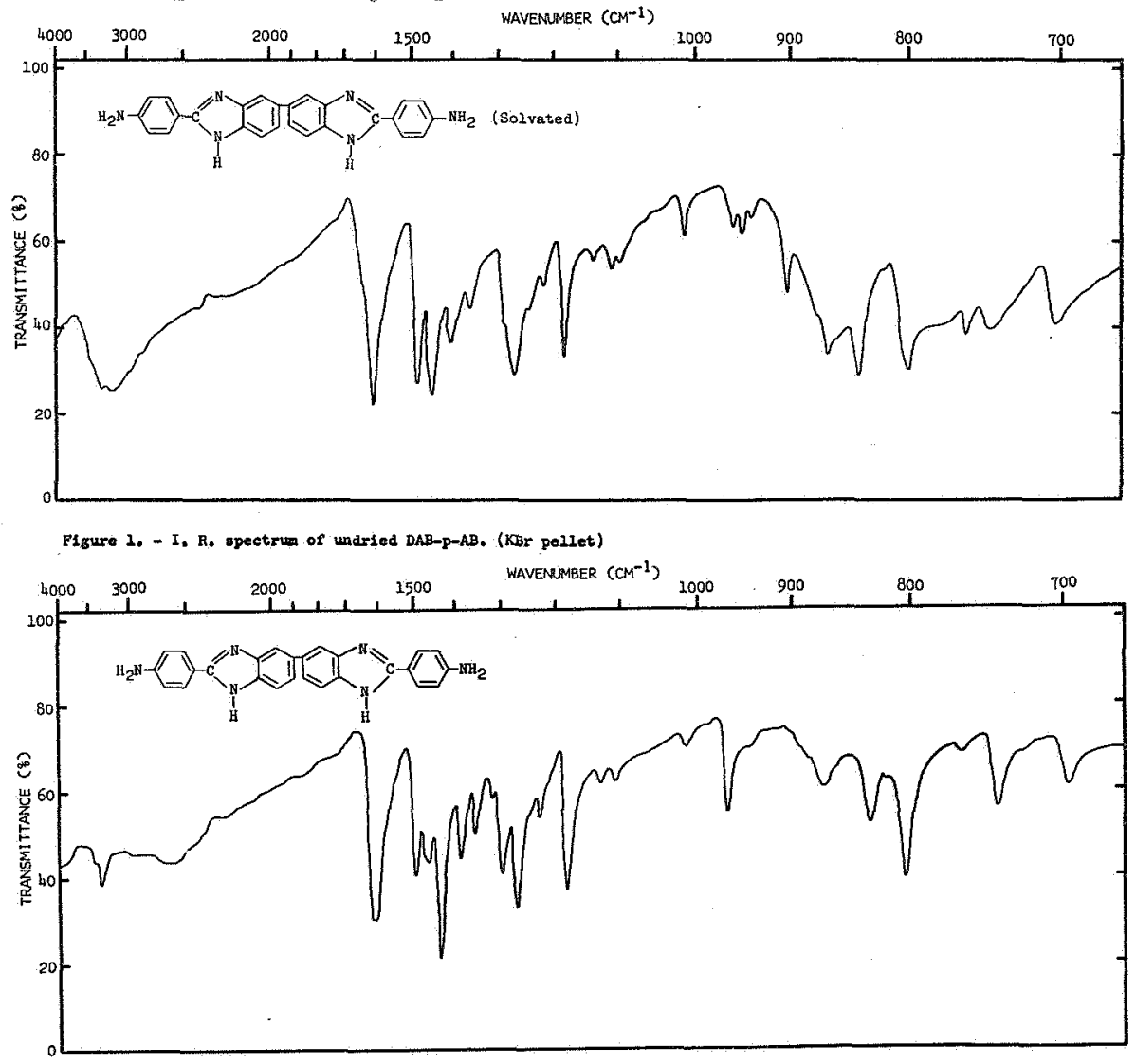

Figure 2. - I. R. spectrum of dried DAB-p-AB. (KBr peilet)

The differential thermal analysis (DTA) curves of undried DAB-p-AB and $T A B-p-A B$ (Figs. 3 and 4) suggest strong solvent complexing of these compounds with loss of solvent occurring around $200^{\circ} \mathrm{C}$. 


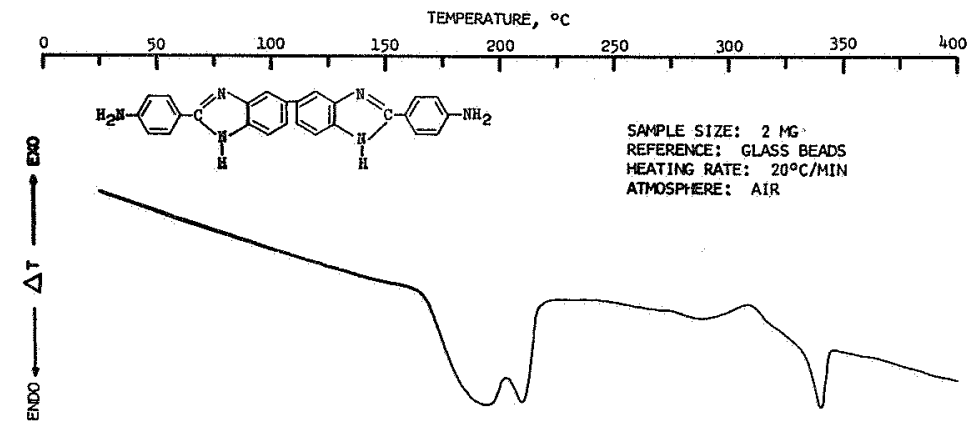
Figure 3. - DTA thermogram of undried DAB-p-AB, showing desolvation near $200^{\circ} \mathrm{C}$ and melting

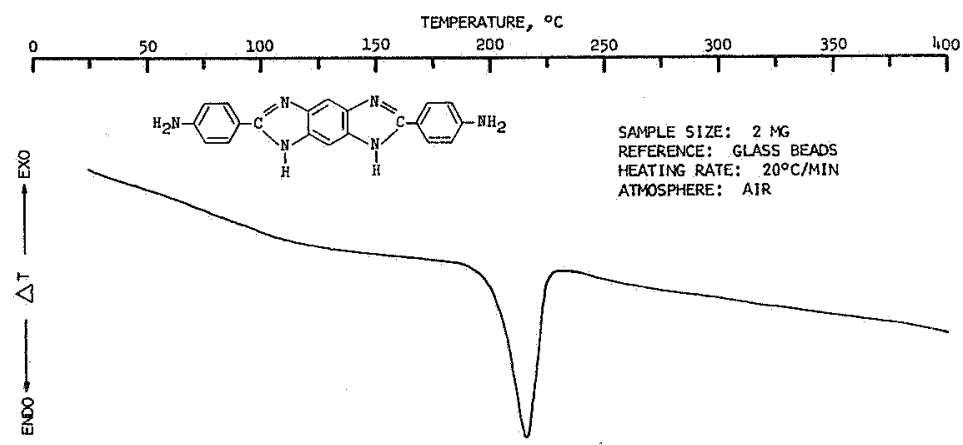

Figure 4. - DTA thermogram of undried TAB-pwAB, showing desolvation near $200^{\circ} \mathrm{C}$.

The infrared spectra of the model compound, 2-aminophenylbenzimidazole, and each of the diamine monomers $D A B-m-A B, T A B-p-A B$, and $T A B-m-A B$ are shown in Figures $5,6,7$, and 8 , respectively. Elemental analyses for each of the undried and dried monomers are summarized in Table $I$. These results are in good agreement with the proposed monomer structures.

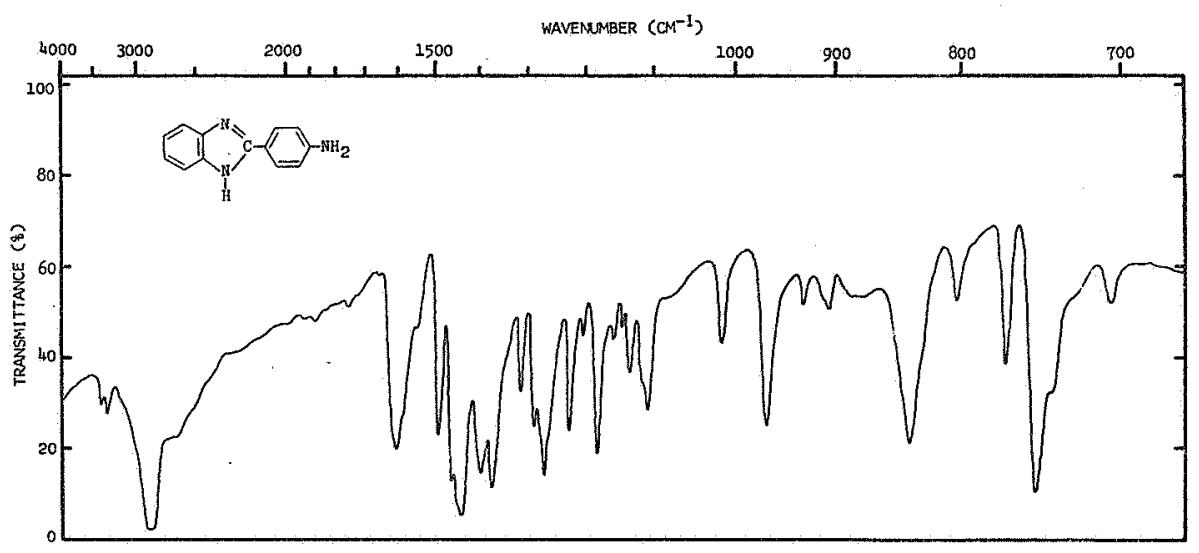

Figure 5. - I. R. spectrum of 2-aminophenyl benzimdazzole, a model conpound for the tronotars. 
5
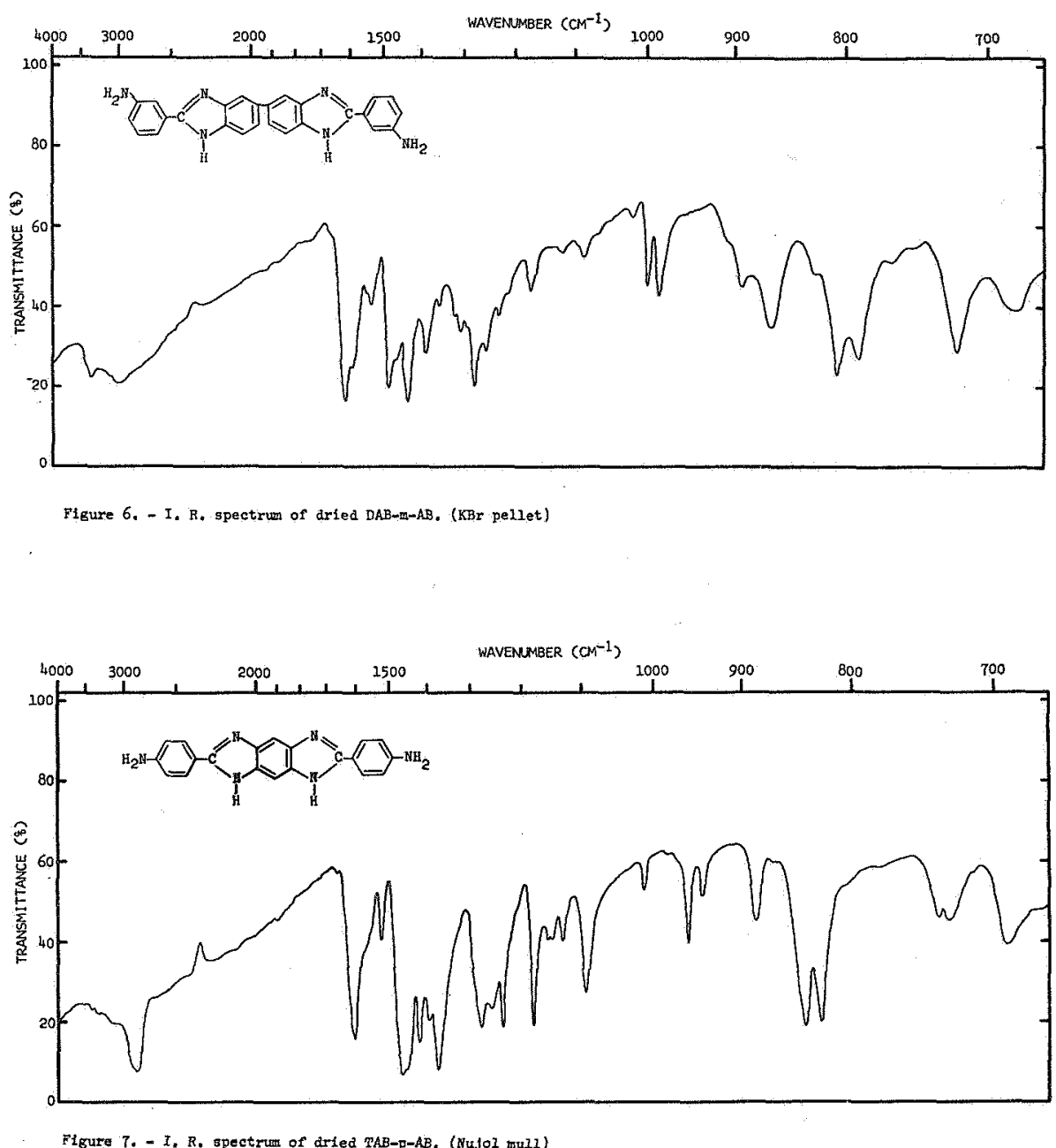

Figure 7. - I. R. spectrum of dried TAB-p-AB. (Nujol mull)

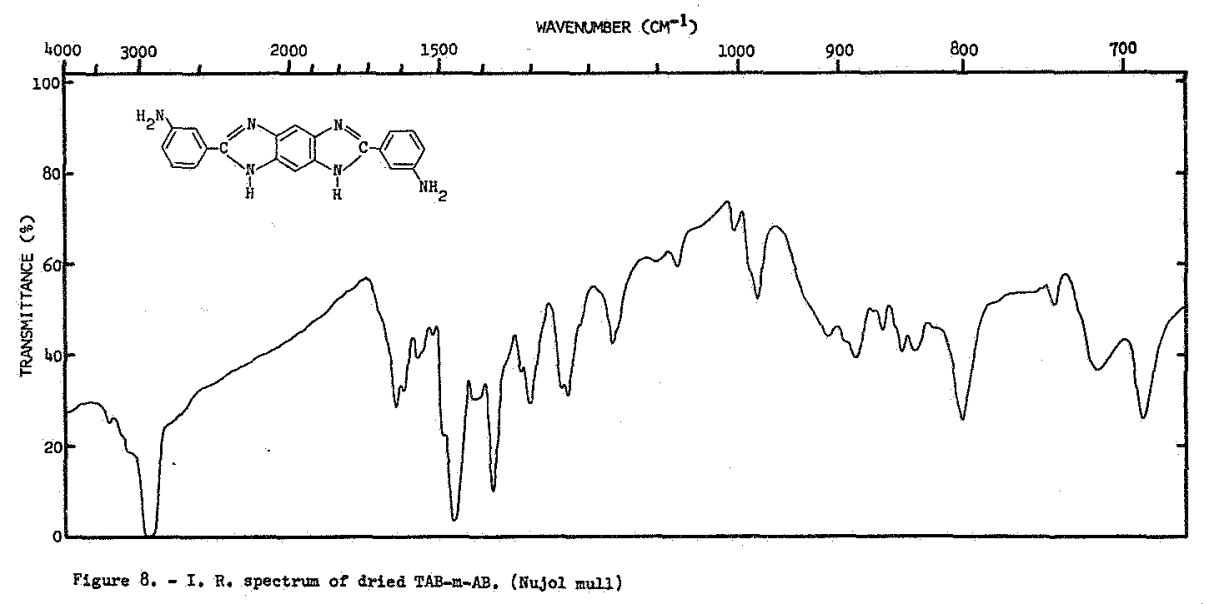


Table I

Elemental Analyses of Monomers

\begin{tabular}{|c|c|c|c|c|c|c|c|}
\hline \multirow[b]{2}{*}{ Compound } & \multirow[b]{2}{*}{ Condition } & \multicolumn{2}{|c|}{ Carbon \% } & \multicolumn{2}{|c|}{ Hydrogen \% } & \multicolumn{2}{|c|}{ Nitrogen \% } \\
\hline & & Calc. & Obs.: & Calc. & Obs. & Calc. & Obs. \\
\hline$D A B=p-A B$ & $\begin{array}{l}\text { Undried } \\
\text { Dried }\end{array}$ & $\begin{array}{l}74.98 \\
74.98\end{array}$ & $\begin{array}{l}68.48 \\
74.90\end{array}$ & $\begin{array}{l}4.84 \\
4.84\end{array}$ & $\begin{array}{l}5.39 \\
4.63\end{array}$ & $\begin{array}{l}20.18 \\
20.18\end{array}$ & $\begin{array}{l}17.61 \\
20.05\end{array}$ \\
\hline$D A B=m-A B$ & $\begin{array}{l}\text { Undried } \\
\text { Dried }\end{array}$ & $\begin{array}{l}74.98 \\
74.98\end{array}$ & $\begin{array}{l}71.53 \\
74.62\end{array}$ & $\begin{array}{l}4.84 \\
4.84\end{array}$ & $\begin{array}{l}4.90 \\
4.64\end{array}$ & $\begin{array}{l}20.18 \\
20.18\end{array}$ & $\begin{array}{l}19.12 \\
19.78\end{array}$ \\
\hline$T A B=p-A B$ & $\begin{array}{l}\text { Undried } \\
\text { Dried }\end{array}$ & $\begin{array}{l}70.60 \\
70.60\end{array}$ & $\begin{array}{l}68.16 \\
70.47\end{array}$ & $\begin{array}{l}4.70 \\
4.70\end{array}$ & $\begin{array}{l}4.94 \\
4.74\end{array}$ & $\begin{array}{l}24.70 \\
24.70\end{array}$ & $\begin{array}{l}22.59 \\
24.66\end{array}$ \\
\hline$T A B-m-A B$ & $\begin{array}{l}\text { Undried } \\
\text { Dried }\end{array}$ & $\begin{array}{l}70.60 \\
70.60\end{array}$ & $\begin{array}{l}68.58 \\
70.52\end{array}$ & $\begin{array}{l}4.70 \\
4.70\end{array}$ & $\begin{array}{l}4.73 \\
4.70\end{array}$ & $\begin{array}{l}24.70 \\
24.70\end{array}$ & $\begin{array}{l}23.05 \\
24.57\end{array}$ \\
\hline
\end{tabular}

Polymerizations

Polymerization procedures were studied thoroughly in order to obtain. high molecular weight aromatic polyamic acids. All solution polymerization methods. In which the aromatic dianhydride solution was added to a solution or slurry of monomer and solvent, failed to yield high molecular weight polymers. The solution polymerization in dimethylacetanide (DMAC), dimethylsulfoxide (DMSO), and N-methylpyrrolidone at room temperature provided only low molecular weight polyamic acid prepolymers. The films from these prew polymers were found to be quite brittle even after only superficial drying at $80^{\circ}-100^{\circ} \mathrm{C}$.

High molecular weight polymers were obtained by the addition of theoretim cal amounts of solid dianhydride to mixtures of monomers and solvent. Dimethylsulfoxide was found to be the most suitable solvent of those examined. The effects of solvent on the intrinsic viscosities of the polymers are summarized in Table II.

Table II

Solvent Effect on Viscosity

\begin{tabular}{|c|c|c|}
\hline Prepolymer & DMSO & DMAC \\
\hline $\begin{array}{l}D A B-p-A B+P M D A \\
D A B=p-A B+B P D A \\
D A B=m-A B+P M D A \\
D A B=m-A B+B P D A \\
T A B=m-A B+P P D A\end{array}$ & $\begin{array}{l}3.3 \mathrm{dl} / \mathrm{g} \\
1.12 \\
0.95 \\
0.80 \\
0.80\end{array}$ & $\begin{array}{l}1.45 \mathrm{~d} l / \mathrm{g} \\
0.59 \\
0.48 \\
\end{array}$ \\
\hline
\end{tabular}


In the polymerization of $D A B-p-A B$ and $T A B-p-A B$ the entixe reaction mixture formed a "gel" after the addition of the theoretical amount of anhydride. This was believed to be due to electrostatic interaction between polymer chains. However, these "gels" could be broken down by stirring vigorously in a Waring Blendor at temperatures below $80^{\circ} \mathrm{C}$.

The polyamic acid prepolymers were cast on glass plates and dried superfically at $85^{\circ}-100^{\circ} \mathrm{C}$ in air for $45-60$ minutes. They were then cured at $280^{\circ}$. $320^{\circ} \mathrm{C}$ in air for periods ranging from 15 minutes to ten hours to bring about ring closure. Lower curing temperatures $\left(e .8 .175^{\circ}-220^{\circ} \mathrm{C}\right.$ ) which have been previously reported $(8)$ invariably led to "flaking" films.

A number of model compounds were prepared and examined to study the spectral changes which accompany the formation of the intermediate acid-amide and subsequent ring closure. These compounds and their respective infrared spectra are given below:

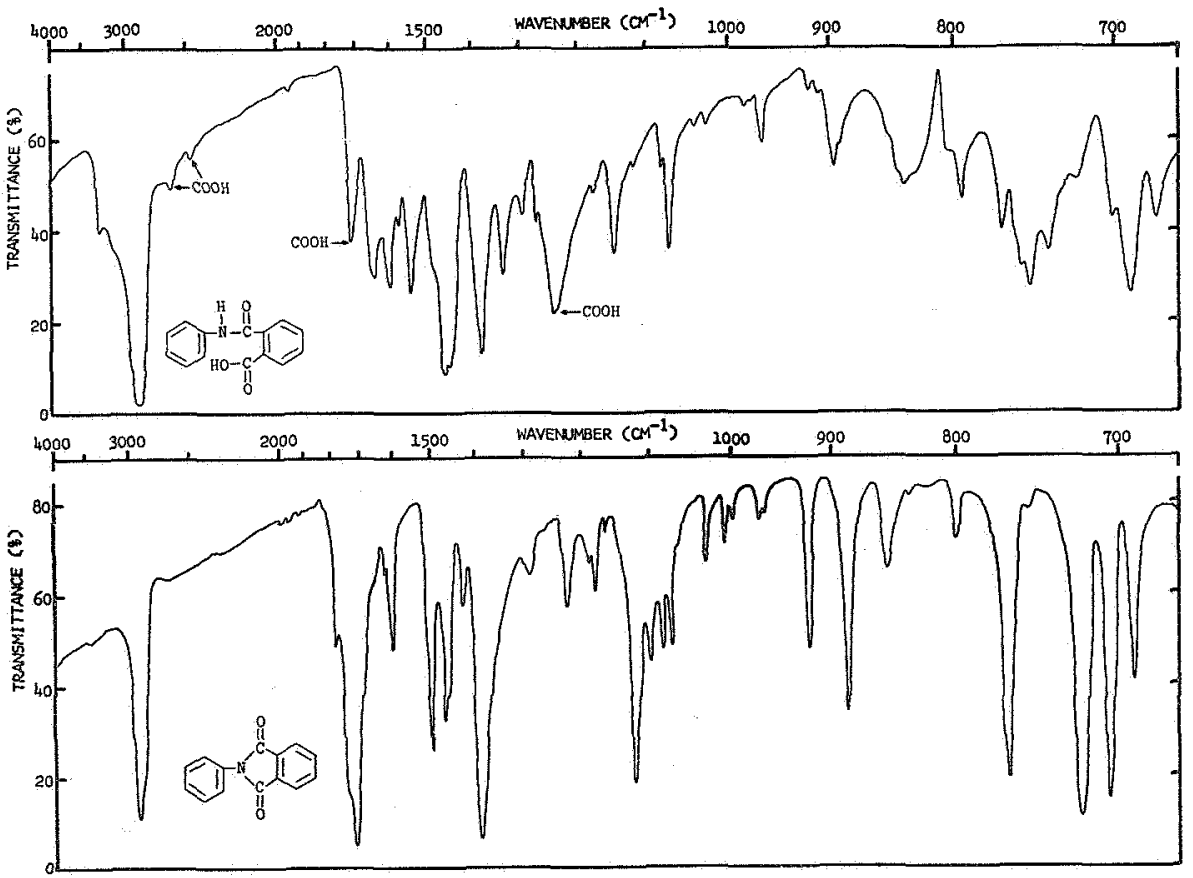

Figure 9. - Above: Phthalo-monomanilide. (Hujol mull)

Belov: N-phenyl phthalinfide. (Nugol mull) 

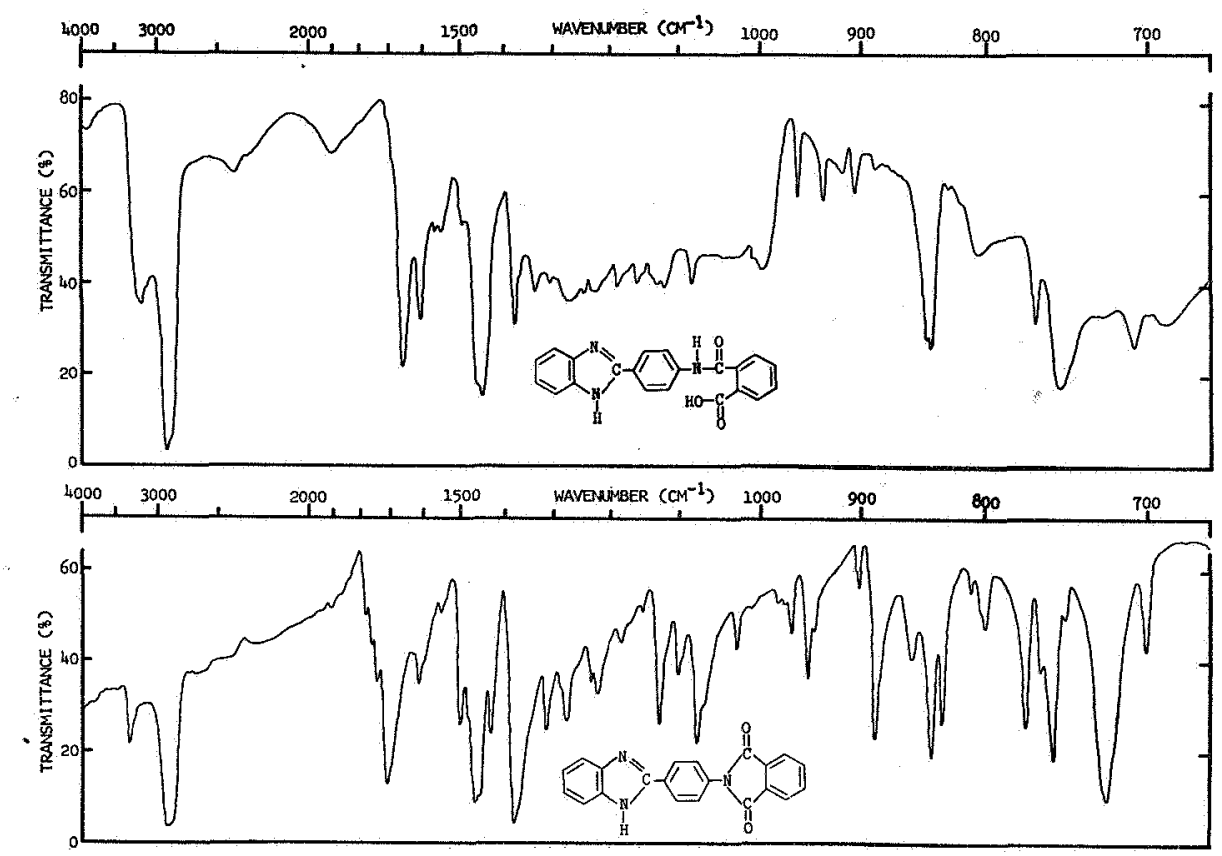

Figure 10. - Above: 2-N-phthaloy I-p-aminophenyl benzimidazole. (Ifujol mul1)

Below: 2-p-Fhtheliminophenyl benzimidazole. (Nujol null)

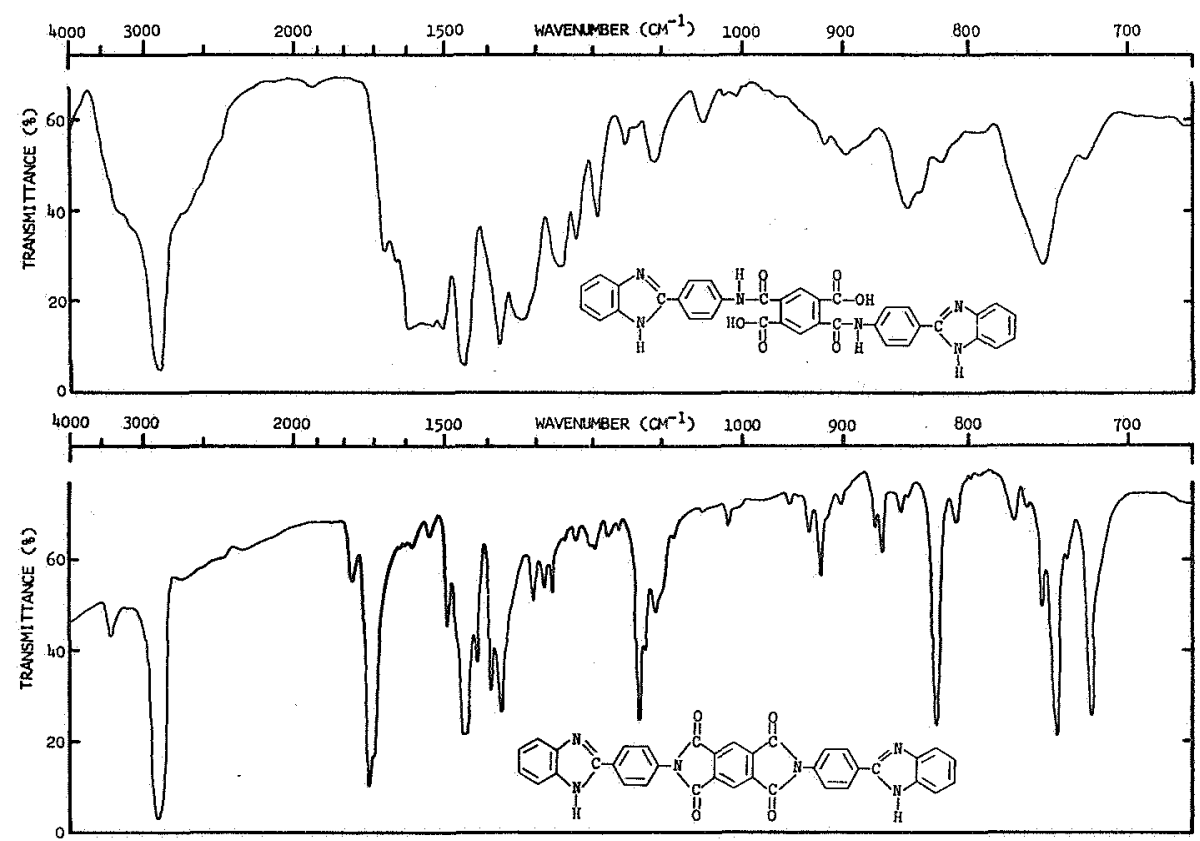

Figure 11. - Above: 1,4, Pyromellito-bis-p-2-benzimidazolylanilide. (Hu,jol muli)

Below: N,N'-p-2-Benzimidazole-phenylpyromelli to-imide. (Nujo1 mull) 

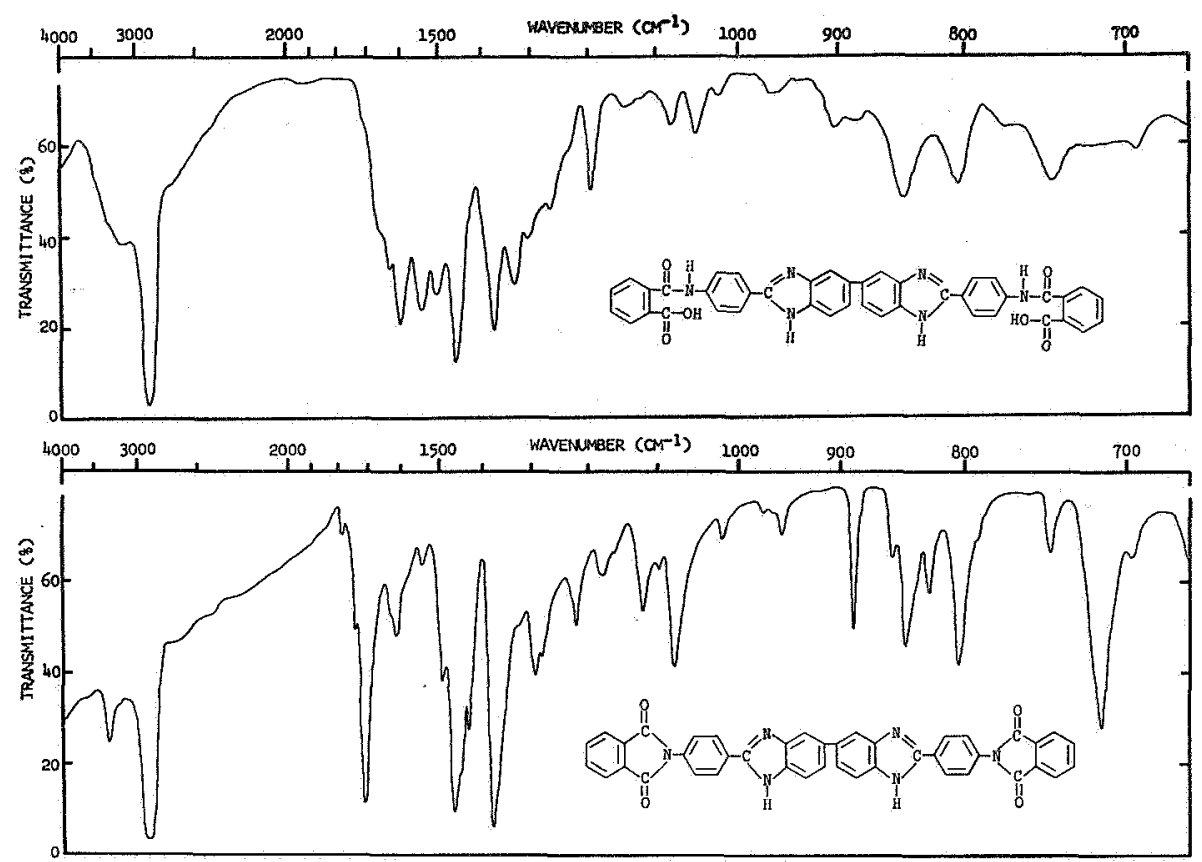

Figure 12. - Above: 2,2'-Di-p-phthalamidophenyl-5,5'-benzimidazole. (Nujol muli)

Belov: $2,2^{4}-$ D1-p-phthailminophenyl-5,5'-bibenzimidazole (Nujol mull)

In some instances, ring closure was accomplished by refluxing in a mixture of Pyridine and acetic anhydride. It was observed that the infrared spectra of the products, obtained either by direct heating or from a refluxing solution, were identical. The infrared spectra of the polyamic-acid prepolymer I and the completely cyclized and cured product II are shown in Figure 13.
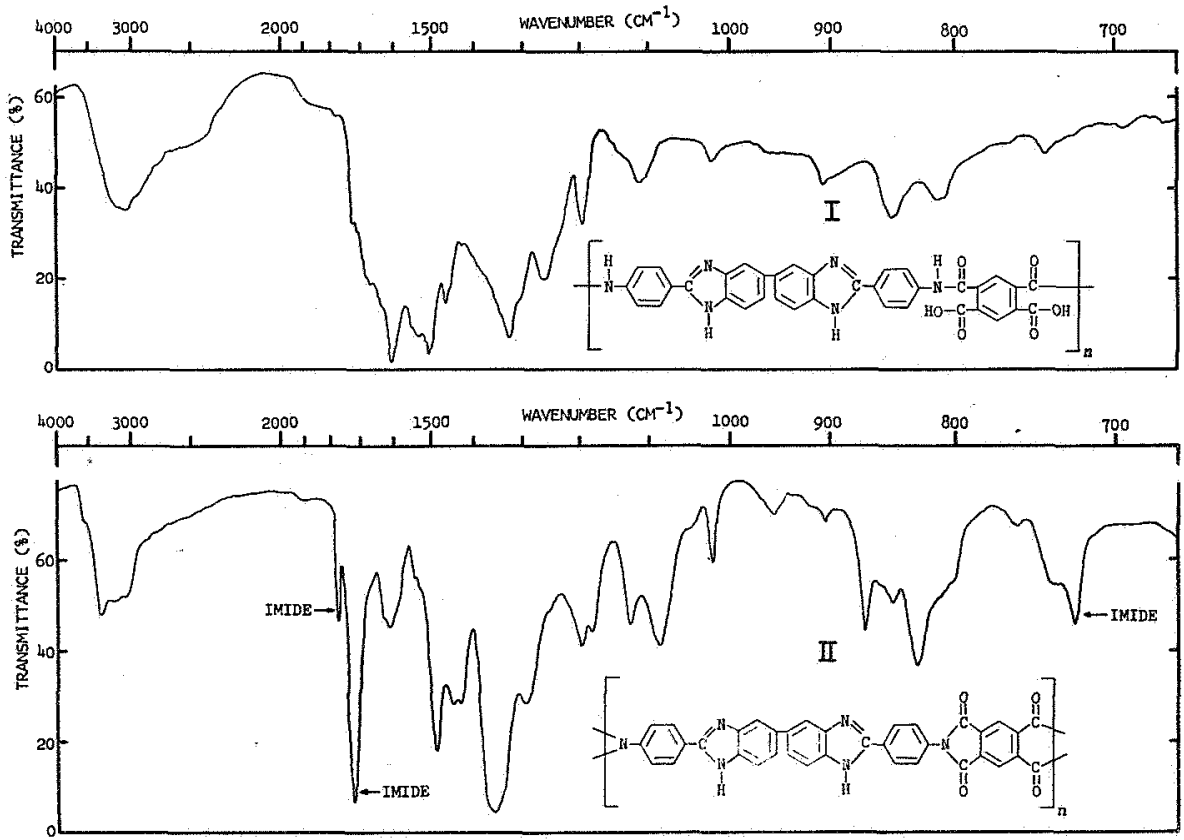

Figure 13. - Above: I. R. spectrum of polyanic acid prepolymer (I).

Belor: I. R. spectrum or benzinidazole-arcmetic imide copolytser (II) from DAB-P $-A B$ and $F M D A$, tormed by ring closure. 
An examination of the infrared spectrum of phthalomonomanilide (Fig.9) discloses that the simplest amidemacid molety can be characterized by absorpa tion peaks at $2400-2700 \mathrm{~cm}^{-1}, 1720 \mathrm{~cm}^{-1}$, and $1230 \mathrm{~cm}^{-1}$, attributable to the carboxyl group. In the more complicated model compounds, which contain the benzimidazole ring, the characteristic carboxyl absorption has been apparently replaced by absorption due to carboxylate ion near $1500 \mathrm{~cm}^{-1}$. Similar peaks are observed for the amidemacids shown in Figures 10,11 , and 12 .

These observations suggest the possibility of salt formation between the carboxylic acid group and the basic benzimidazole ring. The spectra of compounds before ring closure shown in Figures 11 and 12 exhibit a broadening of the absorption in the region of $1700-1500 \mathrm{~cm}^{-1}$. This is due presumably to the combined effects of the un-ionized acid, the carboxylate ion, and the amide groups: however, the carboxylate ion apparently predominates over the unionized acid.

These observations suggest that the polyamic-acid prepolymer structure might be more adequately interpreted as the ionized form shown below, rather than the non-ionized structure previously depicted as I.

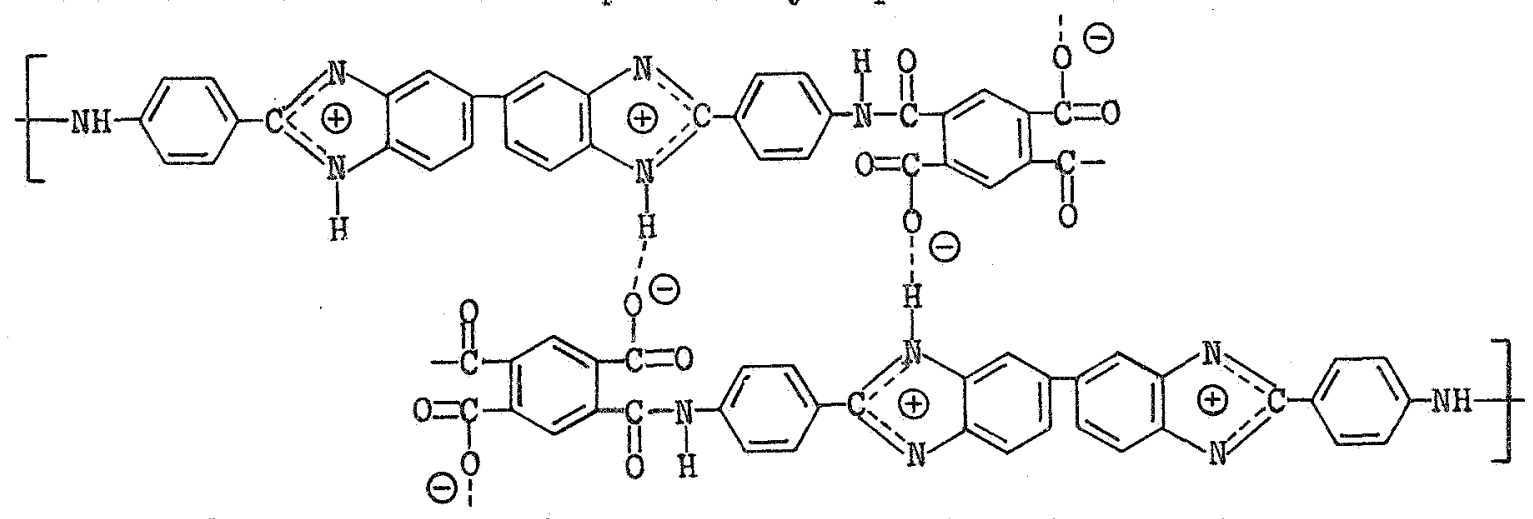

Ionized Form of Structure of Polyamic-Acid Prepolymer

Intexpretation of these results in terms of the polar structure shown above would then account for the observed formation of "gel" on addition of an anhydride. It would also be expected that the tendence of carboxylic acid groups to participate in ring closure would be inhibited by salt formation with the benzimidazole ring, and relatively higher temperatures would be necessary to bring about the proper ring closure. Consequently, one might anticipate that curine at lower temperatures would lead to chain scission with subsequent "rlaking" of the polymex films. Occurrence of flaking after curing at $175-220^{\circ} \mathrm{C}$ supports this argument.

By heating these model compounds and the polyamic-acid prepolymers typical imide-absorption peaks appeared in the infrared around $1790 \mathrm{~cm}^{-1}$. $1710 \mathrm{~cm}^{-1}$ and $720 \mathrm{~cm}^{-1}$ (Fig. 13). The infrared spectrum of each copolymer film was recorded and found to support the proposed benzimidazole and aromatic imide structures. No substantial changes in the spectra were observed by extending heating times up to at least 7 hours at $300^{\circ} \mathrm{C}$. Elemental analyses for the various polymer films are shown in Table III. 
Table III

Elemental Analysis of Benzimidazolem Aromatic

Copolymers Dried at $80^{\circ} \mathrm{C}$ Under Vacuum sor 10 Hours

\begin{tabular}{|c|c|c|c|c|c|}
\hline & $\%$ & Obs. & Calc. & obs. $\left(\cos x_{0}\right)$ & Obs. $\mathrm{H}_{2} \mathrm{O}$ wt.\% \\
\hline $\begin{array}{c}\mathrm{DAB}=\mathrm{p}-\mathrm{AB}=\mathrm{PMDA} \\
0.5 \mathrm{hr} / 300^{\circ} \mathrm{C}\end{array}$ & $\begin{array}{l}\mathrm{C} \\
\mathrm{H} \\
\mathrm{N} \\
\mathrm{O} \\
\end{array}$ & $\begin{array}{r}65.52 \\
3.52 \\
12.86 \\
18.10 \\
\end{array}$ & $\begin{array}{r}72.34 \\
2.87 \\
14.07 \\
10.71 \\
\end{array}$ & $\begin{array}{r}71.46 \\
2.59 \\
14.03 \\
10.71 \\
\end{array}$ & $(8.32$ \\
\hline $\begin{array}{c}\mathrm{DAB}=\mathrm{m}=\mathrm{AB}=\mathrm{PMDA} \\
\mathrm{Ihr} / 300^{\circ} \mathrm{C}\end{array}$ & $\begin{array}{l}\mathrm{C} \\
\mathrm{H} \\
\mathrm{N} \\
\mathrm{O} \\
\end{array}$ & $\begin{array}{r}64.85 \\
3.63 \\
12.59 \\
18.94\end{array}$ & $\begin{array}{r}72.34 \\
2.87 \\
14.07 \\
10.71 \\
\end{array}$ & $\begin{array}{r}72.43 \\
2.59 \\
13.88 \\
10.71 \\
\end{array}$ & $(6.27$ \\
\hline $\begin{array}{c}D A B=p=A B=B P D A \\
2 \mathrm{hrs} / 300^{\circ} \mathrm{C}\end{array}$ & $\begin{array}{l}\mathrm{C} \\
\mathrm{H} \\
\mathrm{N} \\
\mathrm{O}\end{array}$ & $\begin{array}{r}68.66 \\
3.63 \\
10.94 \\
16.79 \\
\end{array}$ & $\begin{array}{r}73.60 \\
3.02 \\
11.98 \\
11.40 \\
\end{array}$ & $\begin{array}{r}73.10 \\
2.94 \\
11.64 \\
11.40 \\
\end{array}$ & $\begin{array}{r}6.07 \\
(4 \text { and } 6 *) \\
\end{array}$ \\
\hline $\begin{array}{l}\mathrm{DAB}=\mathrm{m}=\mathrm{AB}-\mathrm{BPDA} \\
3.5 \mathrm{hrs} / 300^{\circ} \mathrm{C}\end{array}$ & $\begin{array}{l}\mathrm{C} \\
\mathrm{H} \\
\mathrm{N} \\
\mathrm{O}\end{array}$ & $\begin{array}{r}69.31 \\
3.37 \\
11.06 \\
16.26 \\
\end{array}$ & $\begin{array}{r}73.60 \\
3.02 \\
11.98 \\
11.40 \\
\end{array}$ & $\begin{array}{r}73.32 \\
2.76 \\
11.70 \\
11.40\end{array}$ & $\begin{array}{l}5.47 \\
(5)\end{array}$ \\
\hline $\begin{array}{r}\mathrm{TAB}=\mathrm{D}=\mathrm{AB}=\mathrm{PMDA} \\
0.5 \mathrm{hr} / 300^{\circ} \mathrm{C}\end{array}$ & $\begin{array}{l}\mathrm{C} \\
\mathrm{H} \\
\mathrm{N} \\
\mathrm{O}\end{array}$ & $\begin{array}{r}62.84 \\
3.84 \\
11.45 \\
22.28 \\
\end{array}$ & $\begin{array}{r}68.96 \\
2.71 \\
16.09 \\
12.25 \\
\end{array}$ & $\begin{array}{r}70.84 \\
2.07 \\
12.96 \\
12.25 \\
\end{array}$ & $\begin{array}{l}11.30 \\
(9) \\
\end{array}$ \\
\hline $\begin{array}{c}\mathrm{TAB}-\mathrm{p}-\mathrm{AB}-\mathrm{BPDA} \\
\mathrm{hr} / 300^{\circ} \mathrm{C}\end{array}$ & $\begin{array}{l}\mathrm{C} \\
\mathrm{H} \\
\mathbb{N} \\
\mathrm{O}\end{array}$ & $\begin{array}{r}66.05 \\
3.37 \\
12.00 \\
18.58 \\
\end{array}$ & $\begin{array}{r}70.92 \\
2.90 \\
13.42 \\
12.77 \\
\end{array}$ & $\begin{array}{r}70.67 \\
2.64 \\
12.83 \\
12.77 \\
\end{array}$ & $\begin{array}{l}6.54 \\
(6) \\
\end{array}$ \\
\hline $\begin{array}{c}\mathrm{TAB}=\mathrm{m}=\mathrm{AB}-\mathrm{BPDA} \\
3 \mathrm{hrs} / 300^{\circ} \mathrm{C}\end{array}$ & $\begin{array}{l}\mathrm{C} \\
\mathrm{H} \\
\mathrm{N} \\
\mathrm{O}\end{array}$ & $\begin{array}{r}65.34 \\
3.07 \\
12.03 \\
19.56\end{array}$ & $\begin{array}{r}70.92 \\
2.90 \\
13.42 \\
12.77 \\
\end{array}$ & $\begin{array}{r}70.75 \\
2.21 \\
13.03 \\
12.77 \\
\end{array}$ & $\begin{array}{l}7.65 \\
(6) \\
\end{array}$ \\
\hline $\begin{array}{l}\mathrm{DAB}=\mathrm{m}=\mathrm{AB}=\mathrm{BPDA} \\
0.25 \mathrm{hr} / 300^{\circ} \mathrm{C}\end{array}$ & $\begin{array}{l}\mathrm{C} \\
\mathrm{H} \\
\mathrm{N} \\
\mathrm{O}\end{array}$ & $\begin{array}{r}68.67 \\
3.57 \\
10.94 \\
16.82\end{array}$ & $\begin{array}{r}73.60 \\
3.02 \\
11.98 \\
11.40\end{array}$ & $\begin{array}{r}73.13 \\
2.89 \\
11.65 \\
11.40\end{array}$ & $\begin{array}{r}6.10 \\
-\infty+\infty \\
\end{array}$ \\
\hline $\begin{array}{c}T A B=m=A B=B P D A \\
0.25 \mathrm{hr} / 300^{\circ} \mathrm{C}\end{array}$ & $\begin{array}{l}\mathrm{C} \\
\mathrm{H} \\
\mathrm{N} \\
\mathrm{O}\end{array}$ & $\begin{array}{r}63.52 \\
3.60 \\
11.31 \\
21.57 \\
\end{array}$ & $\begin{array}{r}70.92 \\
2.90 \\
13.42 \\
12.77\end{array}$ & $\begin{array}{r}70.42 \\
2.58 \\
12.54 \\
12.77\end{array}$ & $\begin{array}{l}9.91 \\
-\ldots-\infty\end{array}$ \\
\hline
\end{tabular}

Analyses for $C_{0}$ H (Dumas Method) and N (Kjeldahl Method) were conducted by Micromanalysis, Inc. Wilmington, Delaware.

( ) indicates absorbed water loss up to $250^{\circ} \mathrm{C}$ from TGA data.

* TGA measurement extended to $350^{\circ} \mathrm{C}$ 
Table III gives the results of elemental analyses for $\mathrm{C}, \mathrm{H}, \mathrm{N}$, and $\mathrm{O}$ for seven of the copolymers investigated. Values in the "Calc." column should be compared with those in the column headed "Obs. (Corr.)." This comparison confirms the copolymer structures which are typified by the structure for the $D A B=p-A B$ - PMDA copolymer given in Figure 13.

The experimental quantities in the "Obs." column were corrected for the presence of absorbed water to give the values in the column headed "Obs. (Corr.)." This was done by attributing any excess above the calculated percentage of oxygen to oxygen from absorbed water and calculating the effect which that quantity of absorbed water (listed in the "Absorbed Water" column) would have on the percentages of the other elements. The validity of this procedure is confirmed by the direct thermogravimetric measurement of the percentage of absorbed water in each copolymer, the results of which appear in parentheses in the column headed "Absorbed Water." The larger deviation of corrected values in the shorter cured samples is assumed to be due to the prem sence of unevaporated solvent and absorbed water. Similar water absorption behavior has been observed for polyimidazopyrrolones. (10).

The mechanical properties of the copolymers are summarized in Table IV. Those films containing the paramamobenzoic acid unit exhibit tensile strengths of approximately $25,000 \mathrm{psi}$, while those containing the metaaminobenzolc acid unit have tensile strengths around 17,500 psi. This difference in tensile strength between the two series may be due to the presence of some irregularity present in the main polymer chain due to the presence of the meta isomer.

\section{Table IV}

Mechanical Properties of Copolymer Films Cured for One Hour at $300^{\circ} \mathrm{C}$

\begin{tabular}{|c|c|c|}
\hline & $\begin{array}{l}\text { Tensile } \\
\text { Strength, psi }\end{array}$ & Elongation, \% \\
\hline $\begin{array}{l}D A B=p-A B-P M D A \\
D A B=p-A B=B P D A \\
D A B=m-A B-P M D A \\
D A B=-m=A B=B P D A \\
T A B=p-A B=P M D A \\
T A B=p-A B-B P D A \\
T A B=m-A B=P M D A \\
T A B=m-A B=B P D A\end{array}$ & $\begin{array}{l}24,750 * \\
24,000+ \\
17,600^{*} \\
17,500^{*} * \\
25,600+ \\
27,200+ \\
-\ldots+ \\
17,600 *\end{array}$ & $\begin{array}{l}2.0 \\
3.8 \\
3.5 \\
3.5 \\
1.5 \\
3.3 \\
-. .-+ \\
3.3\end{array}$ \\
\hline
\end{tabular}

In Table $V$ are given the results of a preliminary study of the effects of time at $300^{\circ} \mathrm{C}$ on the mechanical properties of the films. Some variation in these properties with film thickness was observed in certain cases. There were five instances in which casting was made from a concentrated polymer solution 
Table V

Effect of Time at $300^{\circ} \mathrm{C}$ on Mechanical Properties of Copolymer Films

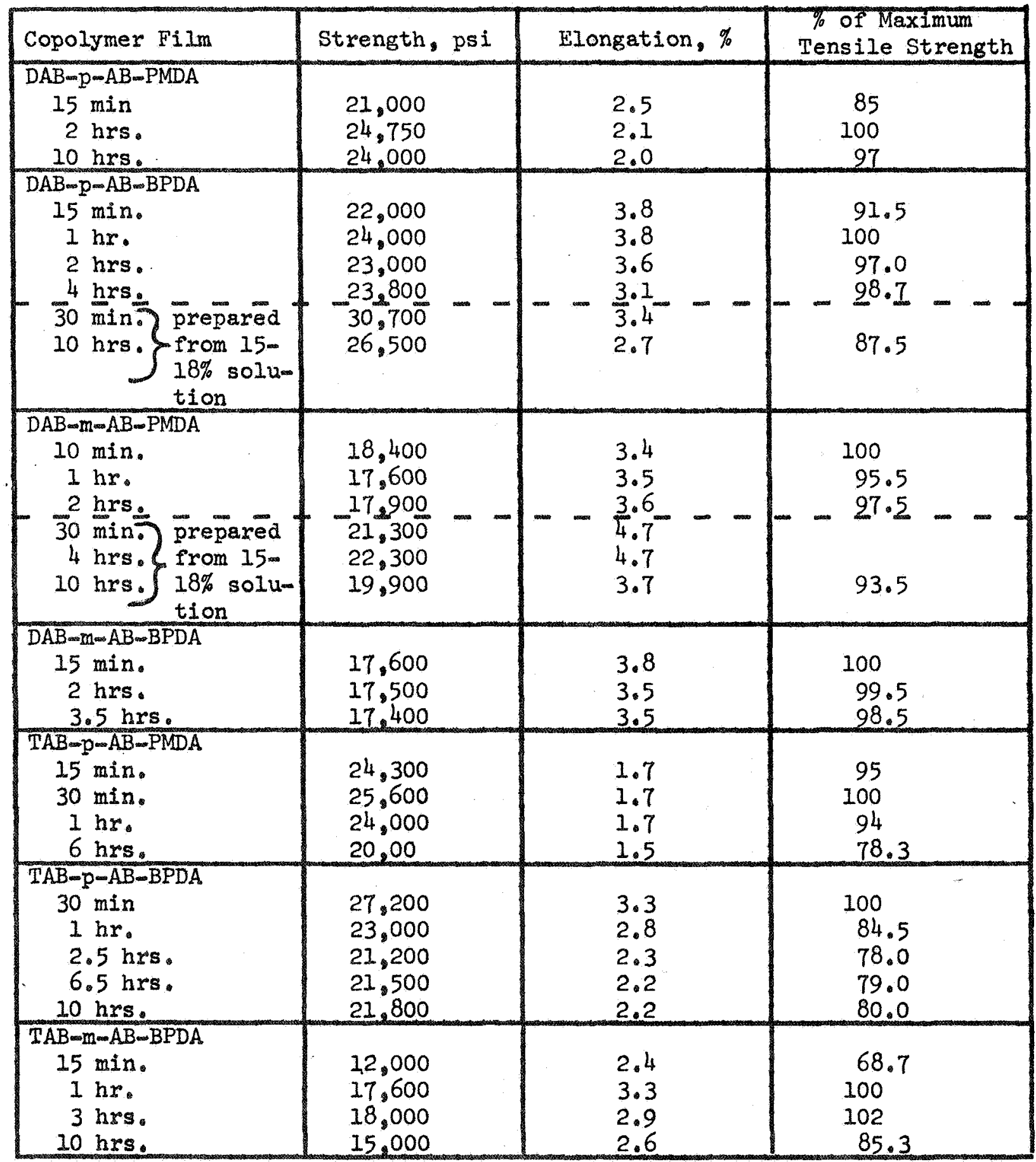


The fully cured copolymer films maintain their strength for at least 10 hours at $300^{\circ} \mathrm{C}$ in air. A minimum curing time of one hour is required to approach maximum tensile strength. Shorter cure times produce incomplete ring closure which results in increased sensitivity to hydrolysis at room temperature. Accordingly, incompletely cured polyamicmacid prepolymers that are exposed to the atmosphere for several months become very brittle, presumably due to hydrolysis of amide groups, acid-catalyzed by neighboring carboxylate groups.

Thermal Stability

The oxidation temperatures of the benzimidazole-aromatic imide copolymer films can be ascertained from their maximum exothermic peaks when evaluated using the DuPont DTA-900 Differential Thermal Analyzer. The results are summarized in Table VI and an example of a typical DTA curve is shown in Figure 14.

Table VI

Oxidation Temperature of Benzimidazole-Aromatic Imide Conolymers

\begin{tabular}{|c|c|}
\hline Copolymer & Oxidation Temp. ${ }^{\circ} \mathrm{C}$ \\
\hline DAB-p-AB-PMDA & 568 \\
DAB-p-AB-BPDA & 586 \\
DAB-m-AB-PMDA & 577 \\
DAB-m-AB-BPDA & 590 \\
TAB-p-AB-PMDA & 568 \\
TAB-p-AB-BPDA & 590 \\
TAB-m-AB-PMDA & 577 \\
TAB-m-AB-BPDA & 590 \\
\hline
\end{tabular}




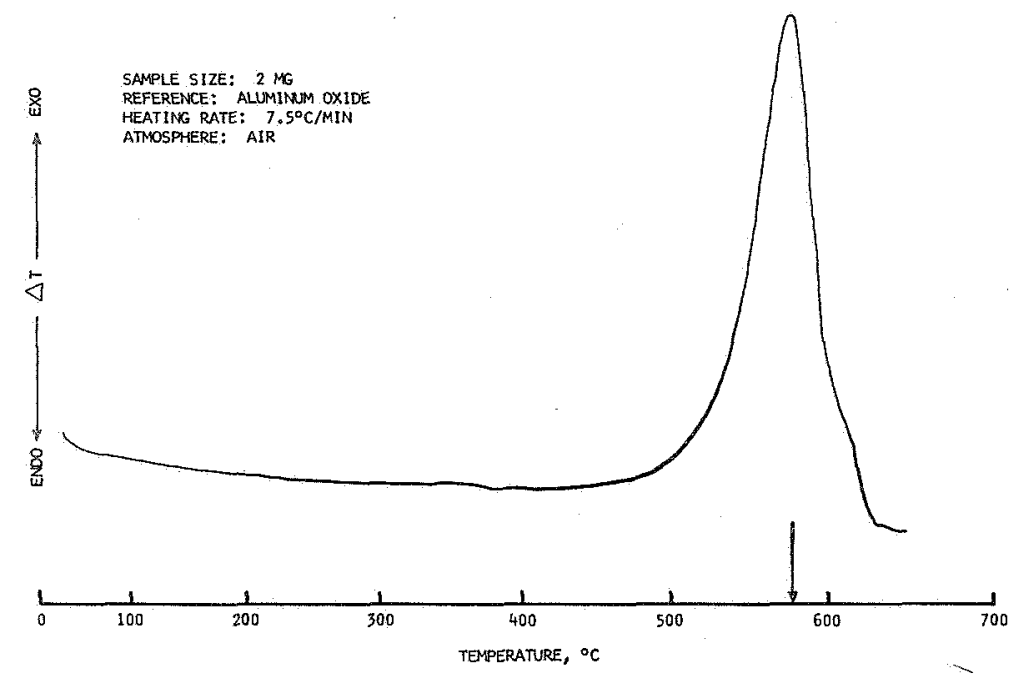

Figure 14. - DNA thermogran of DAB-m-AB-PMDA, run in air.

The DTA studies indicate that there is no significant difference between the thermal stability of the diaminobenzidine and tetraaminobenzene derivatives: however, the metamaminobenzoic acid and benzophenone dianhydride units appear to increase the thermal stability of the polymers to a slight extent.

The thermogravimetric measurements were made both in aix and in vacuo to evaluate the thermal stability of the copolymer. The thermograms prom grammed at a heating rate of $5^{\circ} \mathrm{C}$ pex minute, are summarized in figures 15 ; 16,17 , and 18 . 


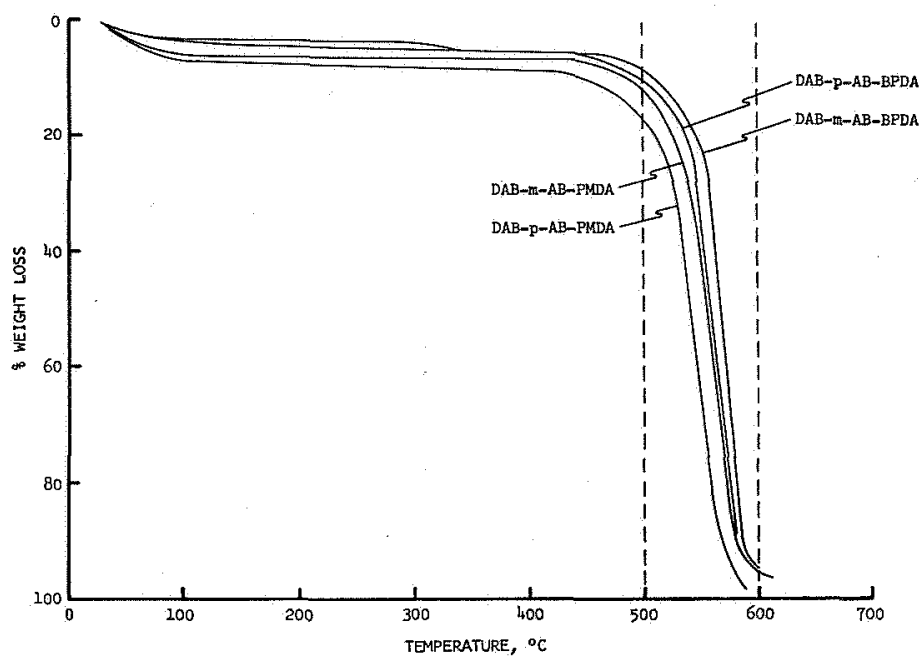

F1gure 15. - TGA thernogrems of $D A B$ copolymers run in air at a $5^{\circ} \mathrm{C} /$ min hesting rate.

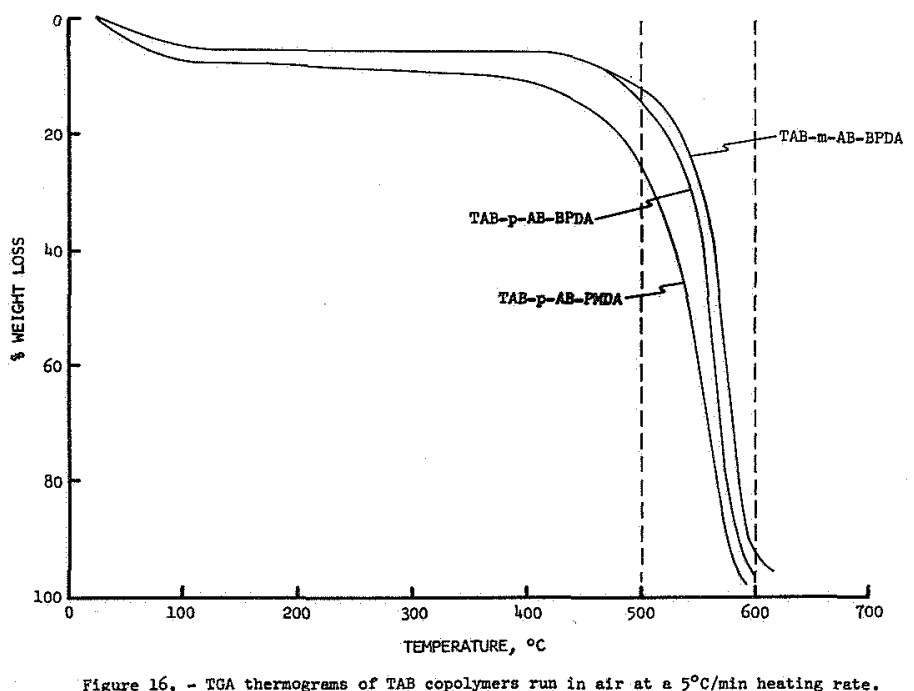




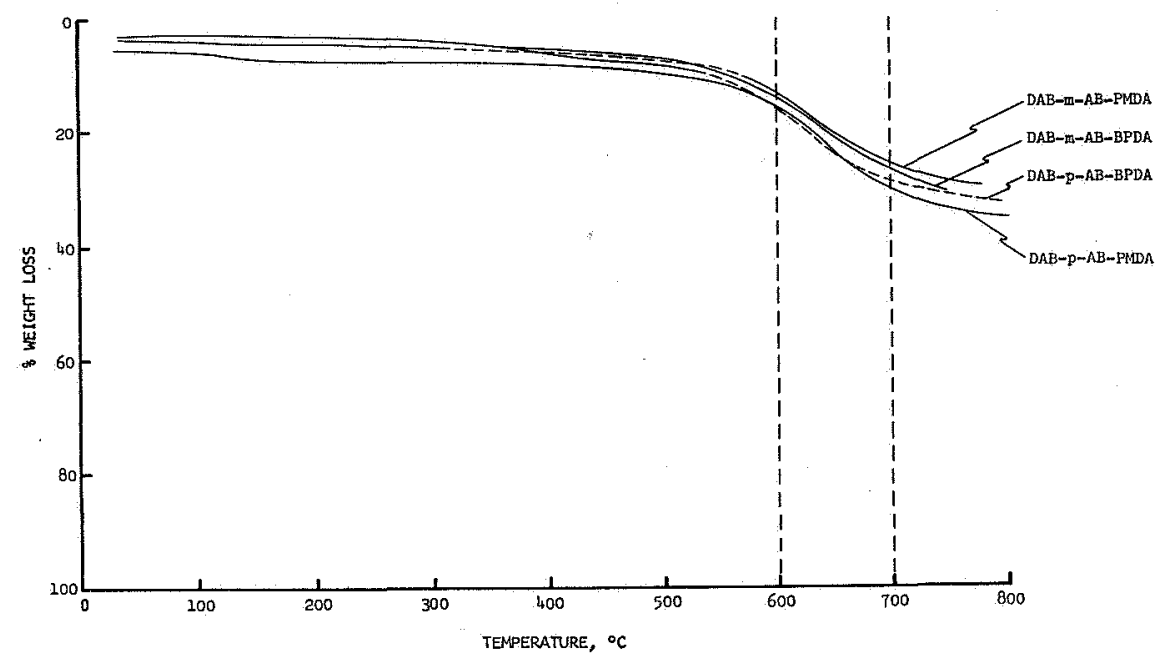

Figure 17. - TGA thermograns of DAB copolymers run in vacwo at a $5^{\circ} \mathrm{C} /$ min heating rete.

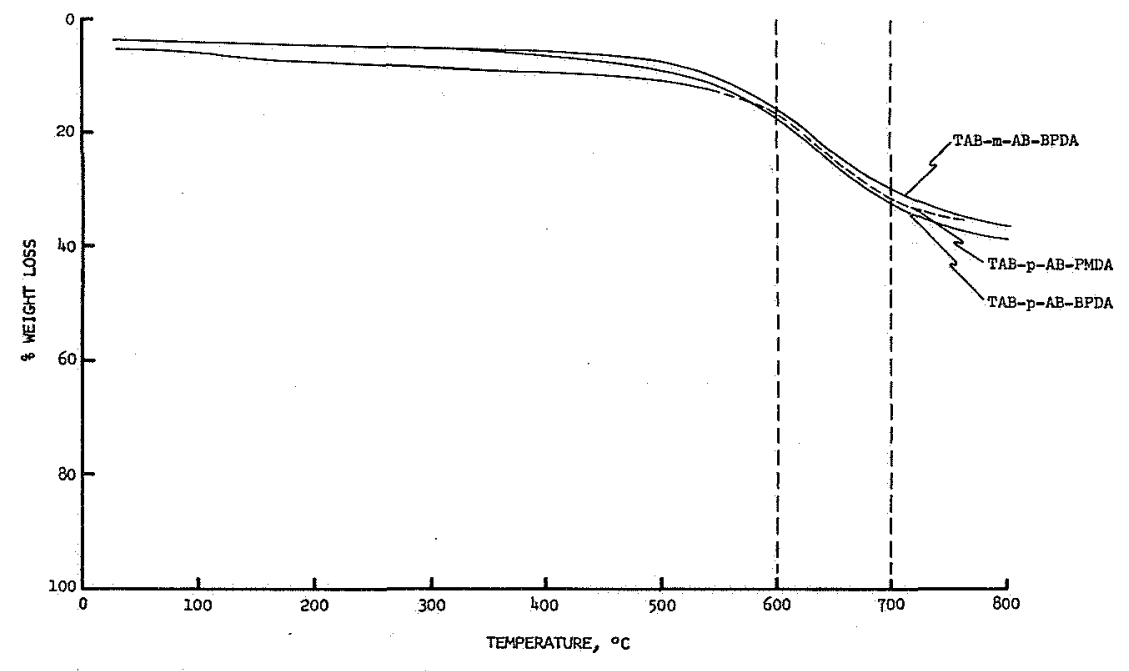

Figure 18. - TGA therrsograms of TAB copolymers run in yacuo at a $5^{\circ} \mathrm{C} / \mathrm{min}$ heating rate. 
The results in Figures $15-18$ show that in air, the $15 \%$ weight loss levels for diaminobenzidine-derived polymers lie in the $520^{\circ}-550^{\circ} \mathrm{C}$ range and $490^{\circ}$. $535^{\circ} \mathrm{C}$ for tetraaminobenzine polymers. The recorded temperatures (corrected for absorbed water) for the diaminobenzidine and tetraaminobenzene polymers in a vacuum are $625^{\circ}-630^{\circ} \mathrm{C}$ and $620^{\circ}-625^{\circ} \mathrm{C}$, respectively. The thermal stability values of the $D A B m-A B$ - PMDA imide copolymer are higher than those previously reported for similar copolymers of $D A B-m-A B$ and $P M D A$.

This report of the excellent thermal stability of the benzimidazolearomatic imide copolymer contrasts somewhat with the data reported previously for the copolymef of diaminobenzidinemetamino benzoic acid and pyromellitic dianhydride 8,9$)$. A more detailed study of these copolymers will be reported in a future publication $(11)$.

Experimental

Properties

Intrinsic Viscosity. - Viscosity measurements were made in $\mathrm{N}, \mathrm{N}$-dimethy 1 acetamide at $25^{\circ} \mathrm{C}$ using Ubbelohde viscometers. The solutions were prepared from polymers which had been precipitated and dried in vacuo, and intrinsic viscosity was measured by a four-point extrapolation to infinite dilution following Huggins' Equation.

Differential Thermal Analysis (DTA). - These measurements were performed on the polymers using a DuPont 900 Differential Thermal Analyzer. The conditions employed have been detailed in figures 3,4 , and 14.

Thermogravimetric Analysis (TGA). - These studies were performed using a null-balancing automatic recording electrobalance (Cahn RG Electrobalance) using polymer sample sizes of $2.05 \pm 0.03$ milligrams. Vacuum measurements were carried out at a pressure of $10^{-6}$ (Torr) which was maintained by an ion pump with a capacity of 250 liters per second.

Mechanical Properties. - The mechanical properties of the polymer films were measured on an Instron Tensile Tester, using film strips 0.5 inch wide with 3.0 inches gage length, and a cross-head speed of 3.0 inches (100\% strain) per minute.

Infrared Spectra. - Infrared spectra were recorded using a Perkin-Elmer Mode1 137 Infrared Spectrometer.

Reagents

3. $3^{B}$-Diaminobenzidine (DAB). - This starting material was obtained from Burdick and Jackson Laboratories. Inc. Muskegon. Michigan and used as received.

1,245 -Tetxaaminobenzene Tetrahydrochlogide - This material was obtained from Burdick and Jackson Laboratories. Inc. and was used without purification. 
Aminobenzoic Acids. Reagent grade $\mathrm{m}$ - and p-aminobenzoic acids were used as received from Fisher Scientific Company.

Pyromellitic Dianhydride (PMDA). - This dianhydride was obtained from Hexagon Laboratories, Inc, New York, $N, Y_{,}$, and Princeton Chemical Company, Princeton, New Jersey. The commercial material was sublimed at $220^{\circ} \mathrm{C} / 0.5 \mathrm{~mm}$ before use.

Benzophenone Tetracarboxylic Acid Dianhydride (BPDA). - BPDA was obtained from Gulf Chemical Company, Pittsburgh, Pennsylvania and was recrystallized from acetic anhydride.

\section{Model Compounds}

Phthalomonoanilide. - Fifty grams $(0.338$ mole) of phthalic anhydride was added with stirring to a solution of $30 \mathrm{~g} .(0.323$ mole) of aniline in $300 \mathrm{ml}$. of benzene at $50^{\circ} \mathrm{C}$. The reaction mixture was allowed to stand at room temperature for one hour. The crystals which precipitated were collected by filtration and recrystallized from ethanol. The yield of colorless crystals, $\mathrm{m} . \mathrm{p} \cdot 183-184^{\circ} \mathrm{C}$, was 70 grams $(88 \%)$.

Anal. Calcd. for $\mathrm{C}_{14} \mathrm{H}_{17} \mathrm{NO}_{3}: \mathrm{C}, 69.69: \mathrm{H}, 4.60 ; \mathrm{N}, 5.81$.

Obs.: $\mathrm{C}, 70.02 ; \mathrm{H}, 4.5 \mathrm{I} ; 3 \mathrm{~N}, 5.94$.

N-Phenylphthalimide. - Ten grams of phthalomonoanilide was heated under a flow of nitrogen for three hours at $230-250^{\circ} \mathrm{C}$. The resulting product, which was insoluble in benzene and ethanol, was recrystallized from tetrahydrofuran to give $7 \mathrm{~g} \cdot(76 \%)$ of colorless crystals, $\mathrm{m}_{\bullet} \mathrm{p} \cdot 209-210^{\circ} \mathrm{C}$.

Anal. Calcd. for $\mathrm{C}_{14} \mathrm{H}_{9} \mathrm{NO}_{2}: \mathrm{C}, 75.32 ; \mathrm{H}, 4.07 ; \mathrm{N}, 6.27$,

Obs : $\mathrm{C}, 75.48 ; \mathrm{H}, 4.10 ; \mathrm{N}, 6.38$.

2-(p-Aminophenyl) benzimidazole. - A solution of $15 \mathrm{~g} .(0.139$ mole) of omphenylenediamine and $22 \mathrm{~g} .(0.160 \mathrm{~mole})$ of pmaminobenzoic acid in aqueous $4 \mathrm{~N}$ hydrochloric acid was refluxed for 70 hours. After the reaction mixture was neutralized with aqueous ammonium hydroxide, the product was collected by filtration and recrystallized from 1:1 ethanol:water. The yield of colorless crystals was $17 \mathrm{~g} .(59 \%), \mathrm{m} . \mathrm{p} \cdot 252^{\circ} \mathrm{C}$.

Anal. Calcd. for $\mathrm{C}_{1} 3^{\mathrm{H}} 11^{\mathrm{N}} 3: \mathrm{C}, 74.60: \mathrm{H}, 5.31 ; \mathrm{N}, 20.08$.

Obs.: C, 74.63; $\mathrm{H}, 5.41 ; \mathrm{N}, 20.23$.

2-(N-Phthaloyl-p=aminophenyl) benzimidazole. - Phthalic anhydride (1.4 g. 0.0095 mole) was added in small portions to a solution of $2.1 \mathrm{~g} .(0.01$ mole) of 2 (paminophenyl) benzimidazole in $10 \mathrm{ml}$. of dimethylformamide at room temperature. The solution was then heated at $100^{\circ} \mathrm{C}$ for 15 minutes during which time a solid precipitated from solution. The yellow crystals which were collected by filtration weighed $3.3 \mathrm{~g} .(97 \%), \mathrm{m} . \mathrm{p} .270^{\circ} \mathrm{C}$.

Anal. Calcd. for $\mathrm{C}_{21} \mathrm{H}_{15} \mathrm{~N}_{3} \mathrm{O}_{3}: \mathrm{C}, 70.37: \mathrm{H}, 4.51: \mathrm{N}_{3}, 11.73$. Obs.: $\mathrm{C}_{8} 71.35: \mathrm{H}_{2} 4.50 ; \mathrm{N}, 11.52$. 
2-(p-Phthaliminopheny 1 ) benzimidazole. - 2-(N-Phthaloyl-p-aminophenyl) benzimidazole was heated at $300^{\circ} \mathrm{C}$ for one hour under vacuum. The resulting yellow solid was washed with ethanol to give a $95 \%$ yield of solid melting at $318-320^{\circ} \mathrm{C}$.

Anal. Calcd. for $\mathrm{C}_{21} \mathrm{H}_{13} \mathrm{~N}_{3} \mathrm{O}_{2}: \mathrm{C}, 74.26 ; \mathrm{H}, 3.87 ; \mathrm{N}, 12.45$. Obs.: $\mathrm{C}, 74.45 ; \mathrm{H}, 3.79 ; \mathrm{N}, 12.66$.

1,4-Pyromeliito-bis(p-2-benzimidazole) anilide. - Pyromellitic dianhydride $(0.5 \mathrm{~g} .0 .0023$ mole) was added with stirring at room temperature to a slurry of one gram $(0.0048$ mole) of 2 -(p-aminophenyl) benzimidazole in $20 \mathrm{ml}$. of dimethylacetamide. The mixture became homogeneous after which precipitation of a solid occurred. The crude product was collected by filtration and washed with ethanol to give an $85 \%$ yield of a light yellow, infusible solid.

Anal. Calcd. for $\mathrm{C}_{36} \mathrm{H}_{24} \mathrm{~N}_{6} \mathrm{O}_{6}: \mathrm{C}, 67.91 ; \mathrm{H}, 3.81 ; \mathrm{N}, 13.20$. Obs.: $\mathrm{C}, 65.01 ; \mathrm{H}, 4.34 ; \mathrm{N}, 12.35$.

Obs. (Corr. as a complex with 5.58 wt. \% of $\mathrm{C}_{2} \mathrm{H}_{5} \mathrm{OH}$ ), C, 67.91; $\mathrm{H}, 3.61$; $\mathrm{N}, 13.07$.

$\mathrm{N}, N^{\prime}-\mathrm{Di}(\mathrm{p}-2$-benzimidazoly 1 pheny 1$)$ oyromellitimide. - The corresponding pyromellitobenzimidazolyl-anilide was heated in a tube under vacuum at $300^{\circ} \mathrm{C}$ for one hour. A golden, infusible solid was obtained which was washed with ethanol. The yield of product was 95\%. The same imidization was carried out by boiling the carboxyanilide in a l:l solution of pyridine and acetic anhy dride for three hours. The solid which precipitated was collected by filtration and washed with ethanol.

Anal. Calcd, for $\mathrm{C}_{36} \mathrm{H}_{20} \mathrm{~N}_{6} \mathrm{O}_{4}: \mathrm{C}, 71.99 ; \mathrm{H}, 3.36 ; \mathrm{N}, 13.66$.

Obs. (via heat): $\mathrm{C}, 71.13 ; \mathrm{H}, 3.39 ; \mathrm{N}, 13.72$.

Obs. (pyridine and acetic anhydride): $\mathrm{C}, 71.21 ; \mathrm{H}, 3.41: \mathrm{N}, 13.92$.

Obs. (Corr. as a complex with 1.65 wt. \% of $\left.\mathrm{C}_{2} \mathrm{H}_{5} \mathrm{OH}\right), \mathrm{C}, 71.99 ; \mathrm{H}, 3.10$; N. 13.95 (via heat).

Obs. (Corr. as a complex with 1.46 wt. \% of $\left.\mathrm{C}_{2} \mathrm{H}_{5} \mathrm{OH}\right), \mathrm{C}, 71.99 ; \mathrm{H}, 3.22$; N, 14.13 (pyridine and acetic anhydride).

2. $2^{i}-D i-(p-p h t h a l a m i d o$ pheny 1$)-55^{\circ}$-bibenzimidazole. - Phthalic anhydride $\left(0.6 \frac{\left.2.4 \times 10^{-3} 3 \text { mole }\right) \text { was added to a mixture of } 0.8 \mathrm{~g} .}{8.9}\left(1.90^{-3} \mathrm{~mole}\right)\right.$ of $2.2^{\circ}$ di-(pamino phenyl)-5.5'bibenzimidazole in $10 \mathrm{ml}$. dimethyl acetamide. The solid which precipitated was washed with alcohol to give a $100 \%$ yield of a light yellow, infusible powder.

Anal. Calcd, for $\mathrm{C}_{42} \mathrm{H}_{28} 8_{6}{ }^{0} 6: \mathrm{C}, 70.77 ; \mathrm{H}, 3.97: \mathrm{N}, 11.79$

Obs.: $\mathrm{C}, 68.43 ; \mathrm{H}, 4.45 ; \mathrm{N}, 11.60$.

Obs. (Corx. as a complex with 4.49 wt. \% of $\left.\mathrm{C}_{2} \mathrm{H}_{5} \mathrm{OH}\right), \mathrm{C}, 70.77$ :, 3.86 ; N. 12.14.

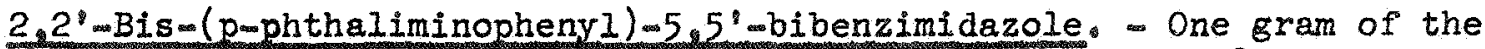
corresponding phthalamidomphenylbenzimidazole was heated at $300^{\circ} \mathrm{C}$ for three hours. A 95\% yield of an infusible, yellow solid was obtained. The reaction 
was also performed by boiling the starting material in a $1: 1$ pyridine: acetic anhydxide solution for three hours. After the mixture was cooled, the solid was collected by filtration and washed with ethanol to give a golden infusible powder.

Anal. Calcd. for $\mathrm{C}_{42} \mathrm{H}_{24} \mathrm{~N}_{6} \mathrm{O}_{4}: \mathrm{C}, 74.54 ; \mathrm{H}, 3.58 ; \mathrm{N}, 12.42$.

Obs. (via heat): $\mathrm{C}, 73.44 ; \mathrm{H}, 3.75 ; \mathrm{N}, 13.33$.

Obs. (Pyridine and acetic anhydride), $\mathrm{C}, 73.13 ; \mathrm{H}, 3.83 ; \mathrm{N}, 12.30$.

Obs. (Corr. as a complex with 2.11 wt. \% of $\left.\mathrm{C}_{2} \mathrm{H}_{5} \mathrm{OH}\right), c, 74.54 ; \mathrm{H}, 3.47$; N. 12.60 (via heat).

Obs. (Corr. as a complex with 2.86 wt. \% of $\mathrm{C}_{2} \mathrm{H}_{5} \mathrm{OH}$ ) $\mathrm{c}, 74.54 ; \mathrm{H}, 3.35$; $N, 12.66$.

Monomers

Diaminophenylbenzimidazoles. -

(a) Using 3, $3^{\circ}$-Diaminobenzidine (DAB) - The tetraamines were dissolved in polyphosphoric acta as a $5 \%$ solution by weight and heated under a protective nitrogen atmosphere. Two molar quantities of the aminobenzoic acid were added at $170^{\circ} \mathrm{C}$ and heating was continued, with stirring, for 10 hours under nitrogen. After the polyphosphoric acid solution was cooled to room temperature, the reaction product was precipitated with water. The solid was collected by filtration, stirred in aqueous ammonium hydroxide solution, filtered and dried. The crude product was purified by dissolving in ethanol and treating with charcoal, followed by filtration and reprecipitation with water.

(b) Using 1,2,4,5-Tetraaninobenzene (TAB) - The tetrahydrochloride salt of TAB was used in the reaction rather than the free base, and the reaction procedure was the same as with DAB. However, the purification procedure for the crude monomers required the use of formic acid to dissolve the product in ethanol. Precipitation of the products was ffected by addition of the formic acid-ethanol solution to dilute ammonium hydroxide after filtration.

Desolvation of all monomers was effected by heating for 3 to 4 hours under a pressure of 1 Torr. DTA investigation of melting point was made on all the monomers but only the $D A B-p-A B$ compound exhibited a melting point, this occurring at about $334^{\circ} \mathrm{C}$ (see Figure 3 ).

\section{Polymerization}

The polymerization procedure involved the addition of the di(aminophenylbenzimidazole) to dimethylsulfoxide which resulted in a slurry or solution, depending on the type of monomer used.

Solid dianhydride powder was added slowly while stixring the mixture at room temperature under nitrogen. When monomers based on m-aminobenzoic acid were polymexized, a smooth, viscous polymer solution was obtained after the stoichiometric amount of dianhydxide had been added. However, when the monomers based on pmaminobenzoic acid were used, a "gel" resulted after 85-95\% 
of the dianhydrides were added. This apparent "gel" could be converted to a smooth polymer solution by stirring the entire mass rapidly in a Waring Blendor, while the remaining dianhydride was added, together with amounts of solvent necessary to give a polymer solids concentration of $6-10 \%$ by weight. The vigorous stirring resulted in an increase in temperature of the solution and it was found that best results were achieved when the temperature was kept at $75-80^{\circ} \mathrm{C}$ for $15-20$ minutes.

The polymer solutions, at room temperatures in the case of m-aminobenzoic acid-derived polymers or at elevated temperatures in the case of p-aminobenzoic acid-derived polymers, were cast onto glass plates and spread with doctor knives. The major part of the solvent was removed by heating in a forceddraft air oven at $85-100^{\circ} \mathrm{C}$ for $1-1.5$ hours. The films were then cured by heating in an oven preheated to $300^{\circ} \mathrm{C}$ for periods ranging from 15 minutes to two hours. The infrared spectra of the films indicated that the imidization reaction was essentially complete within 30 minutes.

\section{Acknowledgement}

This work was carried out under a NASA NASmNRC Resident Research Associateship.

The authors thank Mr. Howard L. Price for making the mechanical property measurements and $\mathrm{Mr}$. Robert $\mathrm{A}$. Jewell for making the TGA measurements.

\section{Bibliography}

1. H. Vogel and C. S. Marvel, J. Polymer Sci., I, 511, (1961).

2. H. Vogel and C. S. Marvel, J. Polymer Sci., AI, 1531 (1963).

3. I. Plummer and C.S. Marvel, J. Polymer Sci. A2, 2559, (1964).

4. W. M. Edward and I. M. Robinson, U. S. Patent 2,710,853 (1955). and U. S. Patent 2,867,609 (1959).

5. G. M. Bower and L. W. Frost, J. Polymer Sci., A7, 3135 (1963).

6. C. E. Sroog, A. L. Endrey, S. V. Abrano, C.E. Berr, W. M. Edwards, and K. L. Oliver, J. Polymer Sci, A3, 1373 (1965).

7. L. W. Frost and I. Kesse, J. Appl. Polymer Sci. 8, 1039 (1964).

8. Y. Iwakura, K. Uno, Y. Imai, and M. Fukui, Makr. Mol. Chem., 72,41 (1964).

9. J. Preston and W. B. Black, Polymer Letter, 3, 845 (1965).

10. R. A. Jewell, unpublished results.

11. T. Kurosaki and R. Jewell, "Thermal Behavior of Benzimidazole-Aromatic Imide Copolymers," to be published later. 